\title{
Correction: Grömminger, S., et al. Fetal Aneuploidy Detection by Cell-Free DNA Sequencing for Multiple Pregnancies and Quality Issues with Vanishing Twins. J. Clin. Med. 2014, 3, 679-692
}

Sebastian Grömminger ${ }^{1, *}$, Erbil Yagmur ${ }^{2}$, Sanli Erkan ${ }^{3}$, Sándor Nagy ${ }^{4}$, Ulrike Schöck ${ }^{1}$, Joachim Bonnet ${ }^{1}$, Patricia Smerdka ${ }^{1}$, Mathias Ehrich ${ }^{5}$, Rolf-Dieter Wegner ${ }^{6}$, Wera Hofmann ${ }^{1}$ and Markus Stumm ${ }^{6}$

1 LifeCodexx AG, Konstanz 78315, Germany; E-Mails: u.schoeck@lifecodexx.com (U.S.); j.bonnet@lifecodexx.com (J.B.); p.smerdka@lifecodexx.com (P.S.);

w.hofmann@lifecodexx.com (W.H.)

2 Bahceci IVF Center, Istanbul 34330, Turkey; E-Mail: erbilyagmur@hotmail.com

3 BioGen Medical Instruments Co. Ltd., Istanbul 34235, Turkey;

E-Mail: sanlierkan@biogen.com.tr

4 Petz Aladár Country Teaching Hospital, Győr 9023, Hungary; E-Mail: nagysandor@gyor.net

5 Sequenom Center for Molecular Medicine, San Diego, CA 92121, USA;

E-Mail: mehrich@sequenom.com

6 Center for Prenatal Diagnosis and Human Genetics Kudamm-199, Berlin 10719, Germany; E-Mails: wegner@kudamm-199.de (R.-D.W.); stumm@kudamm-199.de (M.S.)

* Author to whom correspondence should be addressed; E-Mail: s.groemminger@lifecodexx.com; Tel.: +49-7531-97694702.

Received: 21 November 2014; in revised form: 24 November 2014 / Accepted: 24 November 2014 / Published: 24 November 2014

The authors wish to make the following corrections to this paper [1]:

On page 683 at the end of Section 3.2. lines 13-14, the word "no" is missing.

The correct sentence should be:

"There has been no evidence of false-negative NIPT results so far in the pregnancies included in this study." 
The authors would like to apologize for any inconvenience caused to the readers by these changes.

\section{Reference}

1. Grömminger, S.; Yagmur, E.; Erkan, S.; Nagy, S.; Schöck, U.; Bonnet, J.; Smerdka, P.; Ehrich, M.; Wegner, R.-D.; Hofmann, W.; Stumm, M. Fetal Aneuploidy Detection by Cell-Free DNA Sequencing for Multiple Pregnancies and Quality Issues with Vanishing Twins. J. Clin. Med. 2014, 3, 679-692.

(C) 2014 by the authors; licensee MDPI, Basel, Switzerland. This article is an open access article distributed under the terms and conditions of the Creative Commons Attribution license (http://creativecommons.org/licenses/by/4.0/). 